\title{
Preoperative prediction of significant coronary artery disease in patients with valvular heart disease
}

\author{
D R RAMSDALE，E B FARAGHER，D H BENNETT，C L BRAY，C WARD， D C BETON
}

\begin{abstract}
A prognostic index for predicting significant coronary artery disease was established using multiple logistic regression analysis of clinical data from 643 patients with valvular heart disease who had undergone routine coronary arteriography before valve replacement. The index or equation obtained incorporated the presence of angina, a family history of ischaemic heart disease, age, cigarette smoking habits, mitral valve disease, sex, and electrocardiographic evidence of myocardial infarction. The equation was validated using prospective data from 387 patients with valvular disease and shown to enable almost a third of routine coronary arteriograms to be omitted while maintaining $95 \%$ sensitivity for patients with coronary artery disease.

Similar analysis of the more detailed prospective data produced a second discriminant function incorporating diastolic blood pressure, total cigarettes smoked in life, the severity of angina, family history of ischaemic heart disease, age, current cigarette smoking habits, and the ratio of total to high density lipoprotein cholesterol. This method improved the discrimination between patients with and without coronary artery disease, allowing omission of $30 \%$ of routine coronary arteriograms with $100 \%$ sensitivity for patients with coronary disease and omission of $41 \%$ with a $96 \%$ sensitivity level.
\end{abstract}

\section{Introduction}

In many cardiac centres routine coronary arteriography is performed before valve replacement in all patients over 40 years

\footnotetext{
Regional Cardiac Centre, Wythenshawe Hospital, Manchester M23 9LT

D R RAMSDALE, BSC, MRCP, research fellow in cardiology

D H BENNETT, MD, MRCP, consultant cardiologist

C L BRAY, BSC, FRCP, consultant cardiologist

C WARD, MD, MRCP, consultant cardiologist

D C BETON, BSC, DMRD, consultant radiologist
}

Department of Medical Statistics, University of South Manchester, Withington, Manchester M20 8LR

E B FARAGHER, MSC, FSs, medical statistician of age with valve disease. This is done, firstly, to detect coronary artery disease, which has been shown to be a major determinant of prognosis during and after valve replacement, ${ }^{12}$ and, secondly, to assess the anatomy of the proximal left coronary artery in case selective coronary cannulation and perfusion are necessary at operation. ${ }^{3}$ Several workers ${ }^{4-6}$ have suggested that only patients with angina need coronary arteriography since those without angina are unlikely to have appreciable coronary artery disease. This advice has, however, been shown to be ill-conceived by other studies, ${ }^{7-10}$ which have found an incidence of coronary artery disease of $10-20 \%$ in patients with valvular disease without angina. Since routine coronary arteriography demands extra time, expense, equipment, and irradiation and carries its own (albeit small) morbidity and mortality, ${ }^{11-13}$ it would be useful to have a reliable non-invasive method of predicting those patients least likely to have coronary artery disease, in whom arteriography could be omitted.

Impressive epidemiological evidence ${ }^{14-17}$ has established a strong association between certain clinical characteristics and an increased likelihood of developing the clinical manifestations of coronary artery disease, and some workers ${ }^{16-18}$ have derived from these characteristics methods of predicting an individual's risk of myocardial infarction or sudden cardiac death. ${ }^{19} \mathrm{~A}$ few studies ${ }^{20-25}$ have examined the association between these risk factors and arteriographic evidence of coronary artery disease, but none has investigated the use of a risk-factor profile to predict the presence of coronary artery disease in patients with valvular heart disease.

We carried out two separate studies on patients with valvular disease undergoing routine coronary arteriography before valve replacement. In the first study a discriminant function for identifying patients with and without significant coronary artery disease was established from risk factor data collected retrospectively. Subsequently, a more detailed prospective study was performed both to validate the derived discriminant function and to compute an improved index from the more comprehensive data collected.

\section{Patients and methods}

Retrospective study-The clinical details shown in table I were obtained retrospectively from the case notes of 643 consecutive patients with valvular heart disease who underwent routine coronary 
arteriography from 1 December 1976 to 30 November 1979. Selective coronary arteriograms had been performed by standard techniques, ${ }^{27-29}$ recorded on cine film, and interpreted by a cardiac radiologist without knowledge of the patients' clinical data. Reduction of the diameter of the vessel lumen by $50 \%$ or more ${ }^{30}$ was taken as indicating appreciable coronary artery disease.

Prospective study-The clinical details shown in table II were recorded at the time of admission for cardiac catheterisation from all 387 patients with valve disease undergoing routine coronary arteriography during 1980. After a 16-hour fast, blood was collected for biochemical analysis (see table II). Glucose tolerance tests were carried out when the fasting blood sugar was greater than $6.17 \mathrm{mmol} / \mathrm{l}$ $(111 \mathrm{mg} / 100 \mathrm{ml})$. Standard biochemical techniques were used to measure fasting glucose, ${ }^{31}{ }^{32}$ total $^{33}$ and high-density lipoprotein $(\mathrm{HDL})^{34}$ cholesterol, serum triglycerides, ${ }^{35}$ and urate. ${ }^{36}$ Selective coronary arteriograms were performed as in the retrospective study and reported by the same cardiac radiologist. Coronary artery lesions were recorded on standard coronary artery maps and narrowings of $50 \%$ or more selected to represent appreciable coronary artery disease.

Statistical methods-Separate multiple logistic regression analyses ${ }^{37}$ were applied to the data from the two studies using the GLIM statistical computer package..$^{38}$ The available variables were not all fed into the analysis together, but instead the more informative stepwise approach was adopted. The single variable accounting for the largest proportion of the total variability was identified. Then the variable which when added to the first accounted for most of the remaining variability was found, and so on. At each step the statistical criterion used to decide whether or not to include a variable was the log-likelihood ratio test with the significance level set at $1 \%$. The coefficients of the linear additive model thus derived were used to form a simple prognostic index which could be applied before cardiac catheterisation to identify those patients least likely to have appreciable coronary artery disease. Large scores indicated a high risk of coronary artery disease, while low scores were associated with low risk. Intermediate values were equivocal. Appropriate alterations could be made to the constant term in the index so that a patient with a negative score was deemed not to require coronary arteriography.
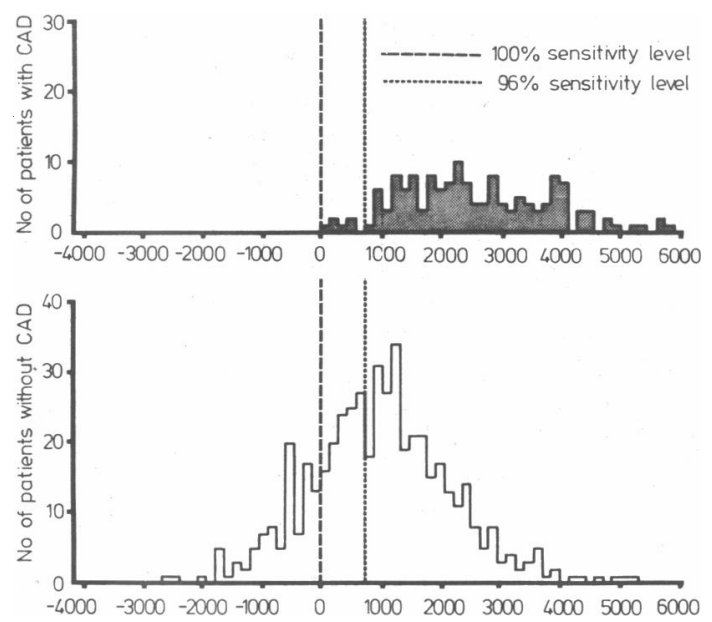

FIG 1-Prognostic indices (or risk factor scores) for patients with and without coronary artery disease (CAD). Retrospective data applied to regression equation derived retrospectively.

TABLE I-Clinical characteristics in 643 patients studied retrospectively

\begin{tabular}{|c|c|}
\hline Variable & Score \\
\hline $\begin{array}{l}\text { Age } \\
\text { Sex } \\
\text { Height } \\
\text { Weight } \\
\text { o' Above mean weight for height } \\
\text { Angina } \\
\text { History of myocardial infarction } \\
\text { History of systemic hypertension } \\
\text { History of diabetes mellitus } \\
\text { Family history of ischaemic heart disease (parents, siblings, } \\
\text { parents' siblings, grandparents) } \\
\text { Regular cigarette smoking (10 year history of } \geqslant 10 / \text { day } \\
\text { within last } 10 \text { years) } \\
\text { Electrocardiographic evidence of myocardial infarction }{ }^{26} \\
\text { Mitral valve disease } \\
\text { Aortic valve disease }\end{array}$ & $\begin{array}{l}\text { Age in years } \\
0=\text { male; } 1=\text { female } \\
\text { Height in cm } \\
\text { Weight in } \mathrm{kg} \\
\%\end{array}$ \\
\hline
\end{tabular}

\section{Results and comments}

RETROSPECTIVE STUDY

The 643 patients (mean age $( \pm S D) 55 \pm 8$ years) consisted of 273 men (mean age $55 \pm 8$ years) and 370 women (mean age $55 \pm 9$ years). Coronary artery disease was found in $147(22.9 \%)$ patients. The variables entered into the regression equation and the scoring system for the prognostic index are shown in table III. The scores obtained by the 643 patients are shown in fig 1 . The constant term was set so that all patients with a negative score were found not to have significant coronary artery disease. Table IV shows the variation in test sensitivity and specificity according to the score chosen to represent a "positiverisk" score (critical score).

\section{PROSPECTIVE STUDY}

The 387 patients (mean age $54 \cdot 6 \pm 9 \cdot 3$ years) consisted of 180 men (mean age $54 \cdot 0 \pm 10 \cdot 7$ years) and 207 women (mean age $54 \cdot 8 \pm 8 \cdot 8$

TABLE II-Clinical characteristics in 387 patients studied prospectively

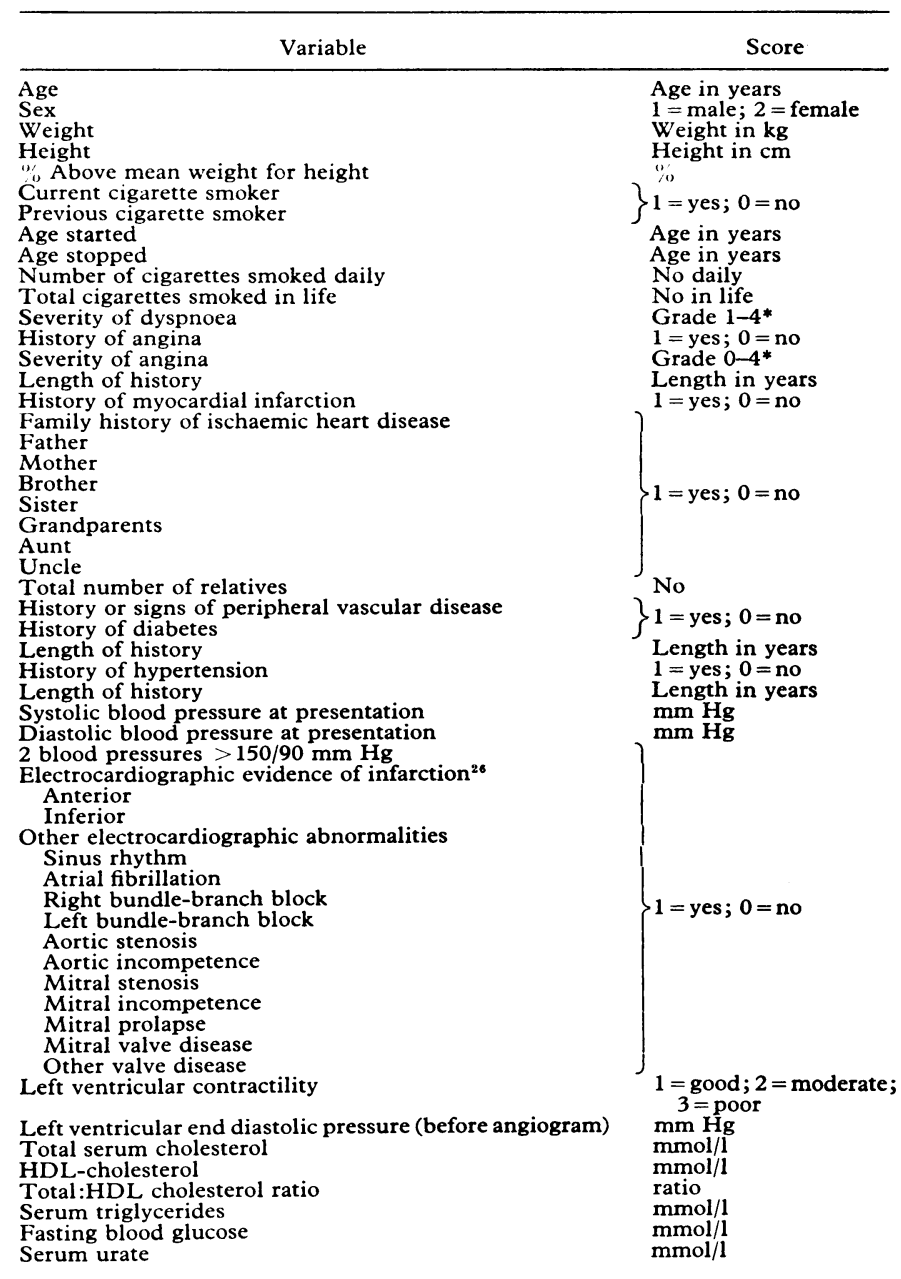

*Grade of dyspnoea and angina: $0=$ absent $; 1=$ on strenuous exertion; $2=0$ on moderate exertion; $3=$ on slight exertion; $4=$ at rest.

TABLE III-Variables entered into regression equation (in order shown) and the scoring system used to develop prognostic index from retrospective study

Constant term

History of angina

Family history of ischaemic heart disease

Age

Cigarette smoking

Mex

Electrocardiographic evidence of myocardial

infarction

-4700
Add 1379 if yes, 0 if no
Add 1250 if yes, 0 if no
Add age (in years) multiplied by 84
Add 1068 if yes, 0 if no
Add 1162 if yes, 0 if no
Subtract 893 if female, 0 if male
Add 1798 if yes, 0 if no

$-4700$

Add 1250 if yes, 0 if $n$

Add 1798 if yes, 0 if no 
BRITISH MEDICAL JOURNAL VOLUME $284 \quad 23$ JANUARY 1982 years). Significant coronary artery disease was found in $112(28.9 \%)$ patients.

Validation of the discriminant function using the prospective dataApplying a prognostic index to the patients from whom it has been derived may produce biased favourable results. The index was thus applied to the 387 patients studied prospectively, and the sensitivity and specificity of the test are shown in table V. With the critical score set at 0 , all patients with significant coronary artery disease would have been correctly identified, as would $15 \%$ of those patients without appreciable coronary artery disease (low specificity). In this latter group of patients routine coronary arteriography could have been safely omitted. Raising the critical score to 600 would have resulted in

TABLE IV-Sensitivity and specificity of prognostic index according to definition of critical risk score. Retrospective data from 643 patients applied to regression equation derived retrospectively

\begin{tabular}{lcccc}
\hline & \multicolumn{4}{c}{ Critical risk score } \\
\cline { 2 - 5 } & 0 & 300 & 600 & 750 \\
\hline Number with true-positive result & 147 & 144 & 141 & 141 \\
Number with false-positive result & 400 & 364 & 315 & 288 \\
Number with true-negative result & 96 & 132 & 181 & 208 \\
Number with false-negative result & 0 & 3 & 6 & 6 \\
Test sensitivity $(\%)$ & 100 & 98 & $95 \cdot 9$ & $95 \cdot 9$ \\
Test specificity $(\%)$ & 19 & $26 \cdot 6$ & $36 \cdot 5$ & $\mathbf{4 2}$ \\
$\%$ Coronary angiograms saved & $14 \cdot 9$ & 21 & $29 \cdot 1$ & $33 \cdot 3$ \\
\hline
\end{tabular}

TABLE V-Sensitivity and specificity of prognostic index according to definition of critical risk score. Prospective data from 387 patients applied to regression equation derived retrospectively

\begin{tabular}{lcccc}
\hline & \multicolumn{4}{c}{ Critical risk score } \\
\cline { 2 - 5 } & 0 & 300 & 600 & 750 \\
\hline Number with true-positive result & 112 & 109 & 106 & 106 \\
Number with false-positive result & 214 & 193 & 170 & 160 \\
Number with true-negative result & 61 & 82 & 105 & 115 \\
Number with false-negative result & 0 & 3 & 6 & 6 \\
Test sensitivity $(\%)$ & 100 & $97 \cdot 3$ & $94 \cdot 6$ & $94 \cdot 6$ \\
Test specificity $(\%)$ & $22 \cdot 2$ & $29 \cdot 8$ & 38.2 & $41 \cdot 8$ \\
$\%$ Coronary angiograms saved & $15 \cdot 8$ & $22 \cdot 0$ & 28.7 & $31 \cdot 3$ \\
\hline
\end{tabular}
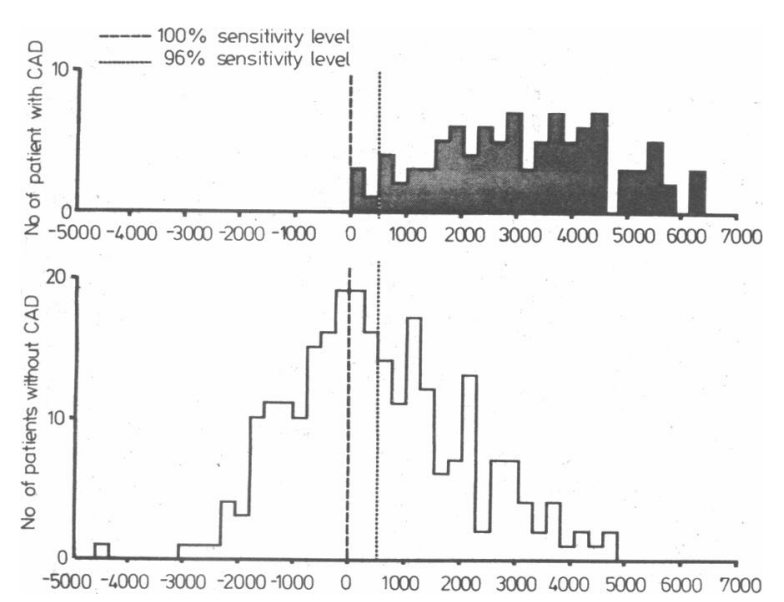

FIG 2-Prognostic indices (or risk factor scores) for patients with and without significant coronary artery disease (CAD). Prospective data applied to regression equation derived prospectively.

TABLE VI-Improved prognostic index from prospective study

\begin{tabular}{ll}
\hline Constant term & -12058 \\
Diastolic blood pressure & Add diastolic blood pressure (in \\
Total number of cigarettes in life* & mm Hg) multiplied by 87 \\
Severity of angina ${ }^{*}$ & Add number multiplied by 0.0106 \\
Family history of ischaemic heart disease & Add severity grade multiplied by 683 \\
Age & Add 1167 if yes, 0 if no \\
Current cigarette smoker & Add age (in years) multiplied by $64 \cdot 6$ \\
Total:HDL-cholesterol ratio & Add 997 if yes, 0 if no \\
& Add ratio multiplied by 196.3
\end{tabular}

*Total $=$ average number smoked annually $\times$ number of years smoking.

† Grading: $0=$ none; $1=$ on strenuous exertion; $2=$ on moderate exertion; $3=0$ on slight exertion; $4=$ at rest.
$5.4 \%$ of those patients with significant coronary artery disease being misdiagnosed, but would have allowed us to omit routine coronary arteriography in almost a third of all patients without significant coronary disease.

Derivation of an improved prognostic index-The variables entered into a second regression equation based on the 387 patients studied prospectively are shown in table VI, together with the scoring system for this "improved" prognostic index. The scores obtained by the 348 patients for whom all the above variables were recorded are illustrated in fig 2. Again, the constant term was adjusted so that all patients with a negative score were found not to have major coronary artery disease. This second index clearly discriminated better between patients with and without major coronary artery disease, although a zone of overlap still existed. With a critical score of 0 coronary arteriograms could have been omitted preoperatively in $29.6 \%$ of patients (those with a negative score) in the knowledge that all patients with significant coronary artery disease would have been correctly identified (see table VII). Increasing the critical score to 500 would have resulted in the omission of over $40 \%$ of routine coronary arteriograms at the expense of missing $4 \%$ of significant coronary artery lesions.

TABLE VII-Sensitivity and specificity of prognostic index test according to definition of critical risk score. Prospective data from 348 patients applied to regression equation derived prospectively

\begin{tabular}{lccc}
\hline & \multicolumn{3}{c}{ Critical risk score } \\
\cline { 2 - 4 } & 0 & 250 & 500 \\
\hline Number with true-positive result & 98 & 95 & 94 \\
Number with false-positive result & 147 & 128 & 112 \\
Number with true-negative result & 103 & 122 & 138 \\
Number with false-negative result & 0 & 3 & 4 \\
Test sensitivity (\%) & 100 & 96.9 & 95.9 \\
Test specificity (\%) & $41 \cdot 2$ & $48 \cdot 8$ & $55 \cdot 2$ \\
\% Coronary angiograms saved & 29.6 & 35.9 & $40 \cdot 8$ \\
\hline
\end{tabular}

\section{Discussion}

Our results show that clinical and laboratory data can be used to identify patients with significant coronary artery disease. We have shown that multivariate analysis of even simple clinical data on risk factors can establish a discriminant function which enables $30 \%$ of routine preoperative coronary arteriograms to be omitted while maintaining a $96 \%$ yield of patients with significant coronary artery disease. By analysing more detailed risk factor data, the discriminant function can be improved even further, so that $30 \%$ of routine coronary arteriograms can be saved without missing any patients with significant coronary disease and over $40 \%$ can be omitted while maintaining $96 \%$ sensitivity for patients with coronary disease.

Application of the multiple logistic regression technique to the prospective data has enabled us to assess the contribution of each factor to the overall angiographic picture of coronary disease. It has taken into account the interdependence of these factors and determined which collectively are most important. A combination of seven characteristics was of particular value in discriminating between those most likely and those least likely to have appreciable coronary artery disease. These characteristics include the severity of angina and five important coronary risk factors-namely, diastolic blood pressure, cigarette consumption, family history of ischaemic heart disease, total:HDL-cholesterol ratio, and age. The importance of the severity of angina is selfevident and the others are well-established as important epidemiological risk factors for the clinical manifestations of ischaemic heart disease. ${ }^{14-17}$ The diastolic blood pressure appears to be a particularly significant independent risk factor for coronary disease in patients with valve disease and is of recognised epidemiological importance in the general population as a whole. ${ }^{39}$ Cigarette smoking features prominently. The total number of cigarettes smoked in life is particularly important, and even though the figure given by a patient is at best only a rough estimate of cigarette consumption, it appears to be more important than the current rate of smoking which has been adopted in most studies. Current smokers appear to be more likely to have significant coronary artery disease than former 
smokers. A family history of ischaemic heart disease may represent the genetic proportion of coronary risk, since other workers have shown that hyperglycaemia, ${ }^{40}$ hyperlipidaemia, ${ }^{41}{ }^{42}$ raised blood pressure, ${ }^{43}$ and low levels of $\mathrm{HDL}^{44}{ }^{45}$ tend to run in families. The total:HDL-cholesterol ratio was found to be the most important lipid predictor of coronary artery disease and this evidence supports previous suggestions from Framingham $^{46}$ that this ratio is the single most useful predictor of risk from coronary heart disease. Age itself is also an important risk factor. Age probably reflects the duration of exposure to the other more important risk factors in addition to its individual correlation with others, such as systolic blood pressure and serum cholesterol, but there may be a more subtle causal relationship between age and the development of coronary artery disease.

This statistical analysis does not imply that those variables excluded from the final equation are not important indicators or predictors of coronary artery disease. It means that after the information in the equation has been taken into account, the remaining variables fail to further discriminate between patients with and without appreciable coronary artery disease. Thus, although the length of history of angina, history of myocardial infarction, diabetes mellitus, systolic blood pressure, serum cholesterol, triglycerides, and urate were significant indicators of the presence of coronary disease in a univariate analysis (unpublished data), these were found to be of little value after the other factors had been taken into account.

This technique of selecting patients with valve disease who are at low risk of coronary artery disease is potentially important in reducing the number of routine coronary arteriograms necessary before valve replacement. This could save time and expense and reduce irradiation exposure and the morbidity and mortality associated with this procedure. Nevertheless, although we have shown that our initial discriminant function is valid by applying it to the prospective data, the "improved index" developed in the prospective study remains unvalidated. It is therefore most important to examine the performance of the improved second equation by applying it to independent data from a new population of patients, and we have recently started such a prospective study.

\section{References}

${ }^{1}$ Linhart JW, de la Torre A, Ramsey HW, Wheat MW. The significance of coronary artery disease in aortic valve replacement. $\mathcal{F}$ Thorac Cardiovasc Surg 1968;55:811-9.

2 Sharratt GP, Rees P, Conway N. Myocardial infarction complicating aortic valve replacement. $\mathcal{F}$ Thorac Cardiovasc Surg 1976;71:869-71.

${ }^{3}$ Swanton RH, Brooksby IAB, Jenkins BS, et al. Determinants of angina in aortic stenosis and the importance of coronary arteriography. Br Heart $\mathcal{F}$ $1977 ; 39: 1347-52$.

4 Bonchek LJ, Anderson RP, Rosch J. Should coronary arteriography be performed routinely before valve replacement? $A m \mathcal{F}$ Cardiol $1973 ; 31$ : $462-6$.

5 Basta NL, Raines D, Najiar S, Kioschos JM. Clinical, haemodynamic and coronary angiographic correlates of angina pectoris in patients with severe aortic valve disease. Br Heart $\mathcal{f}$ 1975;37:150-7.

${ }^{6}$ Baxter RH, Reid JM, McGuiness JB, Stevenson JG. Relation of angina to coronary artery disease in mitral and in aortic valve disease. $B r$ Heart $\mathcal{f} 1978 ; 40: 918-22$.

${ }^{7}$ Harris CN, Kaplan MA, Parker DP, Dunne EF, Cowell HS, Ellestad MH. Aortic stenosis, angina and coronary artery disease. Interrelations. $\mathrm{Br}$ Heart $\mathcal{F} 1975$;37:656-61.

${ }^{8}$ Lacy J, Goodin R, McMartin D, Masden R, Flowers N. Coronary atherosclerosis in valvular heart disease. Ann Thorac Surg 1977;23:429-35.

- Morrison GW, Thomas RD, Grimmer SFM, Silverton PN, Smith DR. Incidence of coronary artery disease in patients with valvular hear disease. Br Heart $\mathcal{F} 1981 ; 44: 630-7$.

${ }^{10}$ Ramsdale DR, Bennett DH, Bray CL, Ward C, Beton DC, Faragher EB. Coronary arteriography prior to valve replacement. Eur Heart $\mathcal{f} 1981$; 2:83-6.

${ }^{11}$ Emanuel R. Coronary arteriography. Br Heart $\mathcal{f} 1975$;37:229-30.

12 Bourassa MG, Noble J. Complication rate of coronary arteriography. A review of 5250 cases studied by a percutaneous femoral technique. Circulation 1976;53:106-14.

${ }^{13}$ Davis K, Kennedy JW, Kemp HG Jr, Judkins MP, Gosselin AJ, Killip T. Complications of coronary arteriography from the Collaborative Study of Coronary Artery Surgery (CASS). Circulation 1979;59:1105-12.
14 Inter-Society Commission for Heart Disease Resources. Primary prevention of the atherosclerotic diseases. Circulation 1970;42:A55.

${ }^{15}$ Keys A, ed. Coronary heart disease in seven countries. Circulation 1970;41, suppl $1: 1-195$

${ }^{16}$ Kannel WB, McGee D, Gordon T. A general cardiovascular risk profile: the Framingham study. Am $\mathcal{F}$ Cardiol $1976 ; 38: 46-51$.

${ }_{17}$ Rosenman RH, Brand RJ, Jenkins CD, Friedman M, Straus R, Wurm M Coronary heart disease in the Western Collaborative Group Study: final follow-up experience of $8 \frac{1}{2}$ years. $\mathcal{F} A M A 1975 ; 233: 872-7$.

18 Truett J, Cornfield J, Kannel WB. A multivariate analysis of the risk of coronary heart disease in Framingham. 7 Chronic Dis 1967;20:511-24.

19 American Heart Association. Coronary Risk Handbook. Dallas: AMA, 1973

${ }^{20}$ Cramér K, Paulin S, Werkö L. Coronary angiographic findings in correlation with age, body weight, blood pressure, serum lipids and smoking habits. Circulation $1966 ; 33: 888-900$.

${ }^{21}$ Hasin Y, Eisenberg S, Friedlander J, Lewis BS, Gotsman MS. Relationships between extent of coronary artery disease and correlative risk factors. Am Heart $\mathcal{F} 1979$;98:555-61.

22 Salel AF, Fong A, Zelis R, Miller RR, Borhani NO, Mason DT. Accuracy of numerical coronary profile: correlation of risk factors with arteriographically documented severity of atherosclerosis. N Engl f Med 1977; 296:1447-50.

23 Anderson AJ, Barboriak JJ, Rimm AA. Risk factors and angiographically determined coronary occlusion. Am $\mathcal{f}$ Epidemiol 1978;107:8-14.

24 Vlietstra RE, Frye RL, Kronmal RA, et al. Risk factors and angiographic coronary artery disease: a report from the coronary artery surgery study (CASS). Circulation 1980;62:254-61.

${ }^{25}$ Dimsdale JE, Hutter AM Jr, Gilbert J, Hackett TP, Block PC, Catanzano DM. Predicting results of coronary angiography. Am Heart $\mathcal{F} 1979 ; 98$ : 281-6.

${ }^{26}$ World Health Organisation. Hypertension and coronary heart disease. Classification and criteria for epidemiological studies. Geneva: WHO, 1959:168,25-7.

27 Sones FM Jr, Shirey EK. Cine coronary arteriography. Mod Concepts Cardiovasc Dis $1962 ; 31: 735-8$.

${ }^{28}$ Zir LM, Dinsmore RE, Goss C, Harthorne JW. Experience with preformed catheters for coronary angiography by the brachial approach Cathet Cardiovasc Diagn 1975;1:303-10.

29 Judkins MP. Selective coronary arteriography. 1. A percutaneous transfemoral technic. Radiology 1967;89:815-24.

${ }^{30}$ Rafflenbeul W, Urthaler F, Lichtlen P, James TN. Quantitative difference in "critical" stenosis between right and left coronary artery in man. Circulation 1980;62:1188-96.

${ }^{31}$ Barham D, Trinder P. Improved color reagent for the determination of blood glucose by the oxidase system. Analyst $1972 ; 97: 142-5$.

${ }^{32}$ Richardson T. A modification of the Trinder autoanalyzer method for glucose. Ann Clin Biochem 1977;14:223-6.

${ }^{33}$ Technicon Instruments Corporation. Cholesterol (enzymatic). Technicon method No SD4-0040PK7 for SMA 11, computer-controlled multichanne biochemical analyzer. Tarrytown, New York: Technicon Instruments Corporation, 1977:1-5.

${ }^{34}$ Lopes-Virella MF, Stone P, Ellis S, Colwell JA. Cholesterol determination in high density lipoproteins separated by three different methods. Clin Chem $1977 ; 23: 882-4$.

35 Technicon Instruments Corporation. Triglycerides (enzymatic). Technicon method No SD4-0039PK 7 for SMA 11, computer-controlled multichannel biochemical analyzer. Tarrytown, New York: Technicon Instruments Corporation, 1977:3-8.

36 Technicon Instruments Corporation. Urate. Technicon method No SD4 $0013 P K 7$ for SMA 11, computer-controlled multichannel biochemical analyzer. Tarrytown, New York: Technicon Instruments Corporation, 1977:1-4.

37 Day NE, Kerridge DF. A general maximum likelihood discriminant. Biometrics 1967;23:313-23.

${ }^{38}$ Baker RJ, Clarke MRB, Nelder JA. Generalised linear interactive modelling (GLIM) system. London: Royal Statistical Society, 1978.

${ }^{39}$ Shurtleff $\mathrm{D}$. Some characteristics related to the incidence of cardiovascular disease and death. Framingham study 18 year follow-up. In: Kannel WB, Gordon T, eds. An epidemiological investigation of cardiovascular disease. Section 30. Washington DC: US Government Printing Office, 1974.

40 Tattersall RB, Fajans SS. A difference between the inheritance of classical juvenile-onset and maturity-onset type diabetes of young people. Diabetes $1975 ; 24: 44-53$.

${ }^{41}$ Schaefer LE, Odlersberg D, Steinberg AG. Heredity, environment and serum cholesterol. A study of 201 healthy families. Circulation 1958 17:537-42.

42 Heiberg A. The heritability of serum lipoproteins and lipid concentrations. A twin study. Clinical Genetics $1974 ; 6: 307-16$.

43 Miall WE. Heredity and hypertension. Practitioner 1971;207:20-7.

44 Nupuf MS, Sutherland WH. High density lipoprotein in children of young men with ischaemic heart disease. Atherosclerosis $1979 ; 33: 365-70$

45 Wilson PW, Garrison RJ, Castelli WP, Feinleib M, McNamara PM, Kannel WB. Prevalence of coronary heart disease in the Framingham Offspring Study: role of lipoprotein cholesterols. Am $\mathcal{f}$ Cardiol 1980; 46:649-54.

${ }^{46}$ Kannel WB, Castelli WP. Is the serum total cholesterol an anachronism ? Lancet 1979 ;ii:950-1.

(Accepted 3 November 1981)

W

\section{\ె}

